\title{
Long-chain $n-3$ polyunsaturated fatty acid from fish oil modulates aortic nitric oxide and tocopherol status in the rat
}

\author{
Diego López ${ }^{1}$, Matías Möller ${ }^{2}$, Ana Denicola ${ }^{2}$, Kelly Casós ${ }^{1}$, Homero Rubbo ${ }^{3}$, José Ignacio Ruiz-Sanz ${ }^{4}$ \\ and Maria Teresa Mitjavila ${ }^{1}$ * \\ ${ }^{1}$ Departament de Fisiologia, Facultat de Biologia, Universitat de Barcelona, Av. Diagonal 645, E-08028 Barcelona, Spain \\ ${ }^{2}$ Departamento de Bioquímica Física, Facultad de Ciencias, Universidad de la República, Montevideo, Uruguay \\ ${ }^{3}$ Departamento de Bioquímica, Facultad de Medicina, Universidad de la República, Montevideo, Uruguay \\ ${ }^{4}$ Fisiologi Saila, Medikuntz eta Odontologi Fakultatea, Euskal Herriko Unibertsitatea, Leioa, Spain
}

(Received 6 June 2007 - Revised 3 January 2008 - Accepted 7 January 2008 - First published online 17 March 2008)

In spite of their high oxidisability, long-chain $n$-3 PUFA protect against CVD. Dietary fatty acids modulate the fatty acid composition of lipoproteins involved in atherosclerosis. We thought that if long-chain $n$-3 PUFA were able to increase NO production by the aorta, then by its antioxidant activity the NO will prevent lipid peroxidation. However, the beneficial effect of NO in vivo on VLDL + LDL oxidation would only be possible if NO could diffuse to their lipidic core. Rats were fed maize oil- or fish oil as menhaden oil- (MO) rich diets for 8 weeks, to study the effects of MO on aortic NO production, NO diffusion into VLDL + LDL, the extent of oxidation in native VLDL + LDL and their oxidisability ex vivo. Aortic NO production and its $\alpha$-tocopherol content were increased and $n-3$ PUFA were incorporated into the VLDL + LDL. In spite of the higher peroxidisability and the low $\alpha$-tocopherol in native VLDL + LDL from rats fed MO, native VLDL + LDL from the two groups shared similar electrophoretic patterns, conjugated dienes, thiobarbituric acid-reactive substances, total antioxidant capacity, and NO diffusibility on VLDL + LDL, indicative of an in vivo protection against oxidation. However, these results do not correlate with the ex vivo oxidisability of VLDL + LDL, as NO is lacking. Thus, the in vivo beneficial effects can be explained by increased $\alpha$-tocopherol in aorta and by a compensatory effect of NO on VLDL + LDL against the low $\alpha$-tocopherol levels, which may contribute to the anti-atherogenic properties of fish oil.

Aorta: Nitric oxide: Paraoxonase-1: Polyunsaturated fatty acids: $\alpha$-Tocopherol

According to the lipoprotein-oxidative theory, oxidised LDL play an important role in initiating the atherogenic process, partly explaining the link between CVD and the lipid profile $^{(1)}$. The LDL particle consists of an apolar core of cholesteryl esters and TAG, surrounded by a monolayer of phospholipids, non-esterified cholesterol, and one molecule of apo B-100. Cholesteryl esters are the predominant lipid class in LDL, are rich in PUFA and thus easily attacked by free radicals. $\alpha$-Tocopherol, the most abundant antioxidant in LDL provides protection to lipid components in LDL.

It has been described that $\mathrm{NO}$ also plays a determinant role in the prevention of lipid oxidation. NO readily crosses cell membranes, concentrates in lipophilic milieu where it reacts to terminate propagation reactions catalysed by lipid alkoxyl and peroxyl radical species ${ }^{(2)}$ and spares $\alpha$-tocopherol ${ }^{(3,4)}$. NO can also diffuse into the lipidic core of the lipoproteins, inhibiting lipid peroxidation processes by these chain-breaking antioxidant properties ${ }^{(5,6)}$. Another antioxidant factor is paraoxonase-1 (PON-1), which is associated with HDL that degrades lipid hydroperoxides protecting LDL from oxidation $^{(7)}$.
Consumption of fish oil or EPA $(20: 5 n-3)$ or DHA $(22: 6 n-3)$ is associated with protection against $\operatorname{CVD}^{(8,9)}$. One of the mechanisms, which have been demonstrated both in human ${ }^{(10)}$ and in rat arteries ${ }^{(11)}$, involves increases in endothelium-dependent vascular relaxation through up-regulation of the endothelial NO synthase-cGMP pathway ${ }^{(12)}$. Longchain $n$-3 PUFA are readily oxidised in vitro in homogeneous systems. However, compared with the intake of $n-6$ fatty acids, the intake of $n-3$ fatty acids prevents the so-called free radical diseases. This suggests that lipid peroxidation in vivo may not correspond with that in vitro ${ }^{(13)}$. For instance, several studies have observed that increasing the dietary intakes of EPA and DHA does not increase the oxidative susceptibility of LDL lipoproteins ${ }^{(14-16)}$. Since molecular order and dynamics within membranes are known to be dependent on acyl chain unsaturation it was generally anticipated that lipid fluidity within lipoproteins will increase when enriched with long-chain $n$-3 PUFA, which in turn will increase $\mathrm{O}_{2}$ diffusibility ${ }^{(17)}$. As the physico-chemical properties of $\mathrm{O}_{2}$ and $\mathrm{NO}$ are very similar it was likely that the diffusibility of NO might also be improved.

Abbreviations: AAPH, 2,2'-azobis (2-amidinopropane) dihydrochloride; CD, conjugated dienes; CO, maize oil; MO, menhaden oil; PON-1, paraoxonase-1; TBARS, thiobarbituric acid-reactive substances.

* Corresponding author: Dr M. T. Mitjavila, fax +34934110358, email mmitjavila@ub.edu 
In the present study we aim to provide new insights into the beneficial effect of fish or fish oil on the prevention of atherosclerosis through the antioxidant activity of $\mathrm{NO}$, to contribute to understanding the mechanism of action of long-chain $n-3$ PUFA. We evaluated the effects of an increase in NO generation at the vascular wall on its $\alpha$-tocopherol content and the diffusion of NO into native lipoproteins. Additionally, we examined by electrophoretic mobility and, through the conjugated dienes (CD), thiobarbituric acid-reactive substance (TBARS) generation and antioxidant levels whether native VLDL + LDL rich in long-chain $n$-3 PUFA were already oxidised. The results were contrasted with the susceptibility to oxidation of VLDL + LDL ex vivo. Furthermore, the contribution of PON-1, an antioxidant enzyme with an indirect action on LDL, was also evaluated.

\section{Materials and methods}

\section{Animals and diets}

After weaning, two groups of male Sprague-Dawley rats (Harlan Interfauna Ibérica, Barcelona, Spain) were fed semipurified diets containing lipids at $50 \mathrm{~g} / \mathrm{kg}$ for 8 weeks, as previously described $^{(11,12)}$. At the end of the feeding period, rats were fasted for $18 \mathrm{~h}$ before exsanguinations by withdrawal of blood from the heart, using heparin as anticoagulant, under sodium urethane $(1.5 \mathrm{~g} / \mathrm{kg}$ intraperitoneally) anaesthesia.

The lipids were either maize oil $(\mathrm{CO})$, rich in linoleic acid $(18: 2 n-6)$, or fish oil as menhaden oil (MO) rich in EPA and DHA. The oils were analysed for tocopherols after extraction with hexane. A sample was mixed with ethanol in the presence of $10 \mu \mathrm{M}$-butylated hydroxytoluene and $5 \mu \mathrm{M}$ - $\alpha$-tocopheryl acetate (internal standard). After filtration a sample was injected into an HPLC (Merck-Hitachi, Darmstadt, Germany) through a column (LiChrospher $100 \mathrm{RP} 18,250 \mathrm{~mm} \times 4.6 \mathrm{~mm}, 5 \mu \mathrm{m}$; Amersham) in methanol-water (95:5) as mobile phase subjected to a flux of $1.5 \mathrm{ml} / \mathrm{min}$. UV absorption at $290 \mathrm{~nm}$ was recorded. The internal standard recovery was $96-98 \%$. The $\mathrm{CO}$ contained $250 \mathrm{mg} R R R$ - $\alpha$-tocopherol $/ \mathrm{kg}$ and $775 \mathrm{mg} R R R$ $\gamma$-tocopherol $/ \mathrm{kg}$, while MO contained $50 \mathrm{mg} R R R$ - $\alpha$-tocopherol/kg, thereby supplying 16.4 and $2.5 \mathrm{mg} \alpha$-tocopherol equivalents $/ \mathrm{kg}$ diet, respectively. The difference in $\alpha$-tocopherol equivalents in oils was eliminated by adjusting diets to $67 \mathrm{mg} R R R$ - $\alpha$-tocopherol equivalents/ $\mathrm{kg}$ by supplementing the $\mathrm{CO}$ diet with $75.6 \mathrm{mg} / \mathrm{kg}$ and the MO diet with $96.3 \mathrm{mg} / \mathrm{kg}$ of all-rac- $\alpha$-tocopheryl acetate. All dietary components were from Sigma (St Louis, MO, USA) with the exception of mineral (35 AIN-76) and vitamin (10 AIN-76A, vitamin E omitted) mixes, which were obtained from ICN Pharmaceuticals (Costa Mesa, CA, USA). The fatty acid content of CO and MO was evaluated after a direct transmethylation ${ }^{(18)}$ and the fatty acid methyl esters were analysed with an HP5890 series II gas chromatograph fitted with a flame ionisation detector. Samples were injected through the split injection port (split ratio, 30:1) onto a SP 2330 capillary column $(30 \mathrm{~m} \times 0.25 \mathrm{~mm}, 0.20 \mu \mathrm{m}$ film thickness; Supelco, Bellefonte, PA, USA) ${ }^{(19)}$. Individual fatty acids were identified by comparing relative retention times with commercial standards (Nu Chek; Elysian, MN, USA). Heptadecanoic acid was used as an internal standard. The double-bond index $\left(\sum\right.$ each fatty acid $\%(\mathrm{~mol} / \mathrm{mol}) \times$ double-bond number $)$ and the theoretical peroxidisability index $\left(\sum\right.$ each fatty acid $\%(\mathrm{~mol} / \mathrm{mol}) \times($ double-bond number -1$))$ were also evaluated. Results are shown in Table 1.

Plasma was stored at $-80^{\circ} \mathrm{C}$ in the presence of sucrose $(60 \mathrm{mg} / \mathrm{ml})$ to prevent changes in the oxidisability indices of lipoproteins during storage. The thoracic and abdominal aorta were dissected out and cut into segments ${ }^{(11)}$. The procedures and animal care were in compliance with European Union guidelines.

\section{Isolation of $V L D L+L D L$ and evaluation of their fatty acid} composition

It is noteworthy that in rat samples the LDL concentration is the smallest fraction of plasma lipids. This is the opposite of what happens in humans ${ }^{(20)}$, and this is why we have used VLDL + LDL.

VLDL + LDL were isolated following the technique of Esterbauer et al. ${ }^{(21)}$ with modifications. Plasma $(3 \mathrm{ml})$ density was adjusted to $1.063 \mathrm{~g} / \mathrm{ml}$ by adding solid $\mathrm{NaBr}$ and then overlaid with $2 \mathrm{ml}$ of PBS (pH 7.5) containing 0.01\% EDTA adjusted to $1.063 \mathrm{~g} / \mathrm{ml}$. Samples were centrifuged at $100000 \mathrm{~g}$ at $4^{\circ} \mathrm{C}$ for $18 \mathrm{~h}$, and the top layer (about $1 \mathrm{ml}$ ) was recovered. Excess $\mathrm{NaBr}$ and EDTA in VLDL + LDL were removed using a PD10 column (Amersham Pharmacia Biotech, UK) and VLDL + LDL were concentrated (Biomax membrane $10000 \mathrm{Da}$; Millipore, Bedford, MA, USA). Proteins were quantified by the Bradford method (Bio-Rad, Hercules, CA, USA). The VLDL + LDL samples were immediately used for electrophoretic studies and oxidation kinetics, and the remaining solution was frozen in the presence of $0.2 \mathrm{~mm}$-butylated hydroxytoluene for $\alpha$-tocopherol analysis.

The evaluation of fatty acid composition of VLDL + LDL was conducted as described for dietary oils.

$N O$ production by the aorta and NO diffusion to $V L D L+L D L$ NO production ${ }^{(22)}$ was studied immediately after extracting the aortae. Two segments of the thoracic aorta $(5-10 \mathrm{mg})$

Table 1. Fatty acid content in oils

(Mean values)

\begin{tabular}{|c|c|c|}
\hline & Maize oil & Menhaden oil \\
\hline $14: 0(\% \mathrm{~mol})$ & 0.19 & 11.9 \\
\hline $16: 0(\% \mathrm{~mol})$ & $11 \cdot 8$ & $18 \cdot 1$ \\
\hline $16: 1 n-7(\% \mathrm{~mol})$ & $10 \cdot 6$ & $14 \cdot 8$ \\
\hline $17: 0(\% \mathrm{~mol})$ & 4.54 & 0.49 \\
\hline $18: 0$ (\% mol $)$ & $2 \cdot 18$ & 3.01 \\
\hline $18: 1 n-9-\operatorname{cis}(\% \mathrm{~mol})$ & $27 \cdot 4$ & $9 \cdot 44$ \\
\hline $18: 1 n-7(\% \mathrm{~mol})$ & 0.64 & 3.77 \\
\hline $18: 2 n-6(\% \mathrm{~mol})$ & $55 \cdot 1$ & $1 \cdot 27$ \\
\hline $18: 3 n-3(\% \mathrm{~mol})$ & 0.95 & 1.40 \\
\hline $20: 4 n-6(\% \mathrm{~mol})$ & ND & 0.96 \\
\hline $20: 5 n-3(\% \mathrm{~mol})$ & ND & $14 \cdot 0$ \\
\hline $22: 5 n-3(\% \mathrm{~mol})$ & ND & $2 \cdot 80$ \\
\hline $22: 6 n-3(\% \mathrm{~mol})$ & ND & $9 \cdot 16$ \\
\hline Total SFA (\% mol) & $15 \cdot 2$ & 35.0 \\
\hline Total MUFA (\% mol) & $28 \cdot 7$ & 33.0 \\
\hline Total PUFA (\% mol) & $56 \cdot 2$ & $31 \cdot 7$ \\
\hline Total $n-6$ PUFA (\% mol) & $55 \cdot 1$ & $4 \cdot 3$ \\
\hline Total $n-3$ PUFA (\% mol) & 0.95 & $27 \cdot 3$ \\
\hline Double-bond index & 152 & 187 \\
\hline Peroxidisability index & 57 & 125 \\
\hline
\end{tabular}

ND, not detected. 
from the same rat were stripped, pre-incubated at $37^{\circ} \mathrm{C}$ for $20 \mathrm{~min}$ in $1 \mathrm{ml} \mathrm{PBS}$, and then exposed to the spin-trapping agents, $5 \mathrm{~mm}$-diethyldithiocarbamic acid and $50 \mu \mathrm{M}-$ $\mathrm{FeSO}_{4} .7 \mathrm{H}_{2} \mathrm{O}$, for $30 \mathrm{~min}$. An additional segment was endothelium denuded or pre-incubated for $30 \mathrm{~min}$ in the presence of $1 \mathrm{mM}-N^{\mathrm{G}}$-nitro-L-arginine, a NOS inhibitor, to assess the specificity of the assay. Aortic strips were then weighed, frozen in liquid $\mathrm{N}_{2}$, and stored at $-80^{\circ} \mathrm{C}$ for electron spin resonance analysis ${ }^{(11)}$. The resulting signal corresponded to the difference in intensity between a maximum at 3440 gauss and a minimum at 3470 gauss.

The importance of an increase in NO production by aorta is a function of its ability to diffuse to the lipidic core of VLDL + LDL. The diffusion study was conducted according to the method of Denicola et al. ${ }^{(5)}$ after incubating VLDL + LDL with a 0.35 mM-fluorescent probe 1-(pyrenyl)-methyl-3-(9octadecenoyloxy)-22,23-bisnor-5-cholenate (PMCho). Excess PMCho was eliminated with a PD10 column (Amersham) and the eluate was degassed under Ar. The NO concentration of an aqueous solution had already been determined by oxyhaemoglobin. Lipoprotein-PMCho preparation $(10-30 \mu \mathrm{g} / \mathrm{ml})$ was injected into fluorimeter cuvettes in degassed $0 \cdot 1 \mathrm{M}-\mathrm{PBS}$. Subsequently, the NO solution was injected gradually, and the fluorescence (excitation wavelength, $347 \mathrm{~nm}$; emission wavelength, $396 \mathrm{~nm}$ ) was monitored. The results were normalised to a blank and the apparent second-order quenching constants between the excited state probe and NO were calculated from the slope of Stern-Volmer plots.

\section{Oxidative state in vivo}

It was important to elucidate whether native VLDL + LDL were already oxidised and to contrast these results with those of stimulated oxidation of VLDL + LDL ex vivo.

The electrophoretic mobility of lipoproteins was visualised in plasma, pre-stained with Sudan black subjected to PAGE in a non-denaturing discontinuous gradient from $2 \%$ (at the area of application) to $3 \%$ (in the running gel) (Lipofilm kit; Sebia; Issy-les-Moulineaux, France) at $100 \mathrm{~V}$.

The electrophoretic mobility of apo B-100 in VLDL + LDL was also evaluated to detect whether the polypeptide was intact. VLDL + LDL were precipitated with a mixture of acetone and ethanol $(1: 1, \mathrm{v} / \mathrm{v})$ and then delipidated with diethyl ether at $-20^{\circ} \mathrm{C}$. The delipidated lipoproteins were mixed with a buffer containing 2-amino-2-(hydroxymethyl)propane-1,3-diol $\mathrm{HCl}(15.76 \mathrm{~g} / \mathrm{l})$, glycerol $(60 \mathrm{~g} / \mathrm{l})$ and SDS $(60 \mathrm{~g} / \mathrm{l})$. SDS-PAGE was performed in a linear gradient $(4-15 \%)$; each well was loaded with $30 \mu \mathrm{l}$ of sample $(2 \mu \mathrm{g}$ of protein/ $\mu \mathrm{l})$ pre-heated to $80^{\circ} \mathrm{C}$ for $15 \mathrm{~min}$. In some wells, purified apo B-100 (Sigma) was also loaded. Electrophoresis was conducted at $120 \mathrm{~V}$ for $2 \mathrm{~h}$. Gels were fixed in $10 \%$ acetic acid and $25 \%$ isopropanol for $10 \mathrm{~min}$, and then stained with Coomassie blue for $1 \mathrm{~h}$. Completely oxidised samples (exposed to $62.5 \mu \mathrm{M}-\mathrm{CuCl}_{2}$ for $24 \mathrm{~h}$ ) were also loaded as a positive control.

The $\alpha$-tocopherol from $100 \mu \mathrm{g}$ native VLDL + LDL protein was extracted with $5 \mathrm{ml}$ water-methanol-hexane $(1: 1: 3$, by vol.) in the presence of $10 \mu \mathrm{M}$-butylated hydroxytoluene and $5 \mu \mathrm{M}-\alpha$-tocopheryl acetate (internal standard). The hexane phase was evaporated under $\mathrm{N}_{2}$, dissolved in methanol and injected into an HPLC (Merck-Hitachi, Darmstadt, Germany) through a column (LiChrospher 100 RP 18,
$250 \mathrm{~mm} \times 4.6 \mathrm{~mm}, 5 \mu \mathrm{m}$; Amersham) subjected to a $100 \%$ methanol flux of $1.5 \mathrm{ml} / \mathrm{min}$. UV absorption at $290 \mathrm{~nm}$ was recorded. The internal standard recovery was $95-98 \%$.

Total antioxidant capacity in VLDL + LDL was evaluated in $100 \mu \mathrm{g}$ VLDL + LDL protein using a kit (Randox Laboratories; Crumlin, Co. Antrim, UK).

TBARS analysis, as evaluation of malondialdehyde, was performed in $10 \mathrm{mg}$ native VLDL + LDL and in $50 \mu \mathrm{l}$ plasma at $540 \mathrm{~nm}$ and subtracting background absorbance at $620 \mathrm{~nm}$. We used tetraethoxypropane as standard ${ }^{(23)}$. Butylated hydroxytoluene and EDTA were added to avoid oxidation during the process.

PON-1 activity was measured in $20 \mu$ l of plasma after incubation in $100 \mathrm{mM}$-2-amino-2-(hydroxymethyl)propane-1,3diol $\mathrm{HCl}$ buffer $\left(\mathrm{pH} \mathrm{8.0)}\right.$ in the presence of $2 \mathrm{mM}^{-\mathrm{CaCl}_{2}}$ and 2 mM-paraoxon (Sigma). Paraoxon degradation to $p$-nitrophenol was monitored by the absorbance increase at $412 \mathrm{~nm}$ (extinction coefficient $18290 \mathrm{l} / \mathrm{mol}$ per $\mathrm{cm}$ ) for $5 \mathrm{~min}^{(24)}$. One unit (U) of PON-1 corresponds to $1 \mathrm{nmol}$ paraoxon degradation/min.

Aortic $\alpha$-tocopherol levels were also measured. A segment of abdominal aorta $(20 \mathrm{mg})$ was extracted as described for $\beta$ carotene $^{(25)}$. The tissue was homogenised in $1.5 \mathrm{ml} \mathrm{KCl}$ $(11.5 \mathrm{~g} / \mathrm{l})$ and $0.5 \mathrm{ml}$ ascorbic acid $(250 \mathrm{mg} / \mathrm{ml})$; then $2 \mathrm{ml}$ ethanol and $50 \mu$ l retinol $(0.1 \mathrm{~mm})$ (internal standard) were added and the mixture saponified with $1 \mathrm{ml}$ of $10 \mathrm{M}-\mathrm{KOH}$. The internal standard recovery was $94-98 \%$. $\alpha$-Tocopherol was extracted in hexane and evaluated by HPLC at $290 \mathrm{~nm}$ in the same conditions as for VLDL + LDL.

\section{Stimulated oxidation of $V L D L+L D L$ ex vivo}

$\mathrm{Cu}^{2+}$ and 2,2'-azobis (2-amidinopropane) dihydrochloride (AAPH) mimic in different ways the oxidation in the vascular compartment. $\mathrm{Cu}^{2+}$ interacts with an LDL low-affinity binding site and generates $\mathrm{Cu}^{+}$, which produces chain-propagating radicals ${ }^{(21)}$. AAPH generates alkoxyl and peroxyl radicals in the aqueous phase, thus triggering lipid peroxidation independently of transition metals ${ }^{(26)}$.

VLDL + LDL $\left(50\right.$ or $25 \mu \mathrm{g}$ protein/ml for $\mathrm{Cu}^{2+}$ and $\mathrm{AAPH}$, respectively) in oxygenated $\mathrm{PBS}$ at $\mathrm{pH} 7.4$ were incubated at $30^{\circ} \mathrm{C}$, either with $1.25 \mu \mathrm{M}-\mathrm{CuCl}_{2}$ or $1 \mathrm{~mm}-\mathrm{AAPH}$. The formation of $\mathrm{CD}$ was monitored by absorbance at $234 \mathrm{~nm}$ for $6-8 h^{(21)}$. The background signal of an AAPH solution (1 mM) was subtracted from the absorbance values of lipoprotein oxidation assay. The lag time, the oxidation rate and the maximum amount of CD formed (molar extinction coefficient of $29500 \mathrm{M} / \mathrm{cm}$ ) were calculated.

\section{Statistical analysis}

Data are expressed as mean values with their standard errors. The results from MO-fed rats were compared with those obtained from CO-fed rats by the Student's $t$ test for unpaired observations.

\section{Results}

\section{Body weight}

There were no differences in either the growth or final body weight of rats after 8 weeks of diet (328 (SE 6) and 323 
(SE 9) $\mathrm{g}$ for the $\mathrm{CO}$ and MO diets, respectively). Food consumption was also similar in both animal groups.

\section{NO production by the aorta and NO diffusion into} $V L D L+L D L$

After incubating aortic segments with $1 \mathrm{mM}-N^{\mathrm{G}}$-nitro$\mathrm{L}$-arginine, the more prominent electron spin resonance signal was reduced by $90-95 \%$ in all groups, indicating that the signal corresponds to NO. The MO diet induced a $130 \%$ increase in aortic NO production ex vivo (Fig. 1(a)). The endothelium-denuded segments gave a weak signal in all groups, indicating that the endothelium is the main source of NO.

NO diffusion into the lipidic cores of VLDL + LDL was similar in both groups. The Stern-Volmer plots were 2.0 (SE 0.4) and 1.7 (SE 0.4) litres/mmol for CO- and MO-fed rats, respectively (Fig. 1 (b)).

\section{Oxidative status in native $V L D L+L D L$ in aorta and in} plasma

Native VLDL and LDL from rats fed either a $\mathrm{CO}$ - or an MO-rich diet showed similar electrophoretic mobility in a non-denaturing gel (Table 2). Electrophoretic mobility of apo B-100 was similar in both dietary groups (Table 2). However, after oxidation by ex vivo exposure to $\mathrm{Cu}^{2+}$, apo $\mathrm{B}-100$ from rats fed CO- or MO-rich diets was degraded.
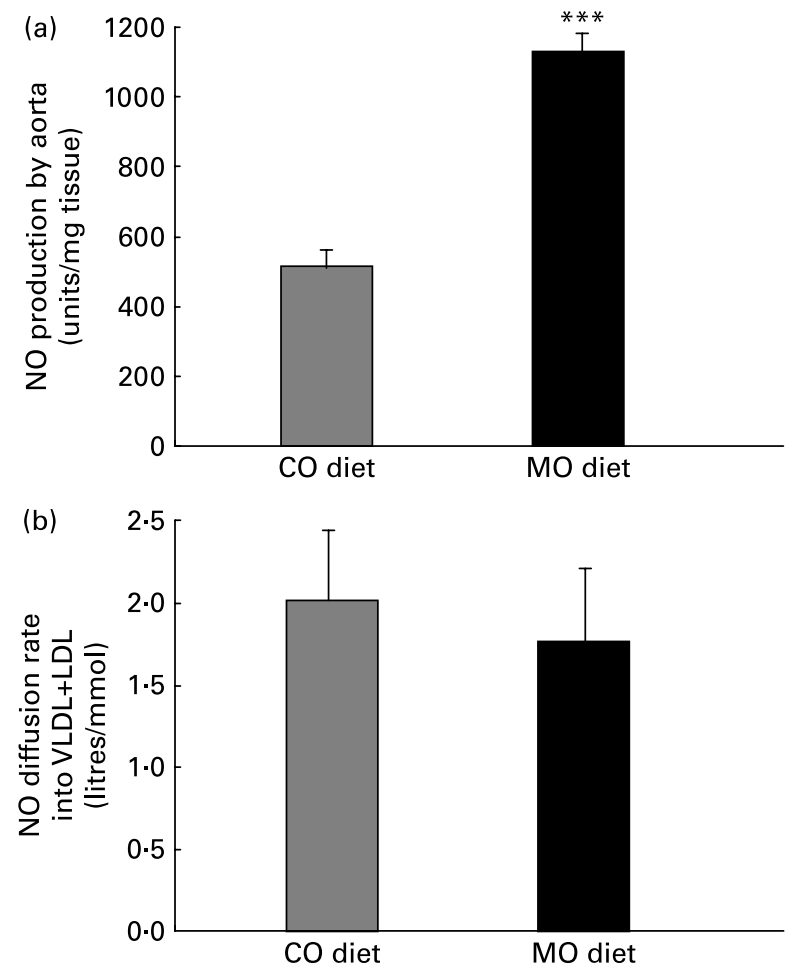

Fig. 1. Aortic NO production measured by electron spin resonance (a) and NO diffusion rate into VLDL + LDL calculated from the slope of Stern-Volmer plots (b) in rats fed a maize oil- (CO) or menhaden oil- (MO) rich diet. Values are the means of six rats per diet with their standard errors represented by vertical bars. ${ }^{* \star *}$ Mean value was significantly different from that of the CO group $(P<0.001)$.
Table 2. Oxidative state in native VLDL + LDL†

(Mean values with their standard errors for six rats)

\begin{tabular}{|c|c|c|c|c|}
\hline & \multicolumn{2}{|c|}{ Maize oil } & \multicolumn{2}{|c|}{ Menhaden oil } \\
\hline & Mean & SE & Mean & SE \\
\hline Electrophoretic mobility of VLDL (Rf) & 0.22 & 0.02 & 0.21 & 0.01 \\
\hline Electrophoretic mobility of LDL (Rf) & 0.33 & 0.02 & 0.32 & 0.02 \\
\hline $\begin{array}{l}\text { Electrophoretic motility of } \\
\text { apo B-100 (Rf) }\end{array}$ & 0.31 & 0.03 & 0.27 & 0.03 \\
\hline Basal CD content (nmol/g protein) & $15 \cdot 2$ & 0.8 & $14 \cdot 6$ & $1 \cdot 2$ \\
\hline Total antioxidant capacity (mmol/l) & 0.32 & 0.02 & 0.27 & 0.01 \\
\hline$\alpha$-Tocopherol (pmol/mg protein) & $12 \cdot 7$ & $0 \cdot 3$ & $9 \cdot 8^{\star \star \star}$ & 0.9 \\
\hline TBARS generation (pmol/mg protein) & 51 & 5 & 64 & 6 \\
\hline
\end{tabular}

$\mathrm{Rf}$, retention factor; $\mathrm{CD}$, conjugated dienes; TBARS, thiobarbituric acid-reactive substances.

*** Mean value was significantly different from that of the maize oil group $(P<0.001)$.

†For details of diets and procedures, see Materials and methods.

The levels of CD in VLDL + LDL were similar in both dietary groups (Table 2).

The total antioxidant capacity in VLDL + LDL from both groups was not statistically different (Table 2 ).

There was a $23 \%$ decrease $(P<0 \cdot 001)$ in the $\alpha$-tocopherol content of VLDL + LDL from rats fed the MO diet compared with rats fed the $\mathrm{CO}$ diet (Table 2). Conversely, there was a $78 \%$ increase $(P<0.001)$ in the aortic tissue $\alpha$-tocopherol content of rats fed the MO-rich diet (32 (SE 3) pmol/mg tissue) compared with rats fed the CO-rich diet (18 (SE 2) $\mathrm{pmol} / \mathrm{mg}$ tissue) (Fig. 2).

We observed no significant differences in the concentration of TBARS either in native VLDL + LDL (Table 2) or in plasma (Table 3).

Similar PON-1 activity in plasma was detected in the two dietary groups (Table 3 ).

\section{Fatty acid composition of VLDL $+L D L$ and stimulated oxidation of $V L D L+L D L$ ex vivo}

The fatty acid composition of VLDL + LDL is shown in Table 4 . The more notable differences appeared in total $n-6$ and $n$-3 PUFA content, which prevail in the lipoprotein fractions of CO- and MO-fed rats, respectively. Thus, VLDL + LDL from CO-fed rats showed higher levels of linoleic acid, $\gamma$-linolenic acid (18:3n-6), arachidonic acid (20:4n-6), and $22: 5 n-6$, while lipoproteins from MO-fed rats showed higher EPA and DHA content. While the theoretical peroxidisability index in rats fed the MO-rich diet was higher than in rats fed the CO-rich diet, due to the levels of highly unsaturated fatty acids, the double-bond index was similar in both dietary groups.

The MO-rich diet altered the oxidation susceptibility of VLDL + LDL when exposed to $1.25 \mu \mathrm{M}-\mathrm{CuCl}_{2}$ or to $1 \mathrm{mM}-$ AAPH (Fig. 3(a)). With $\mathrm{Cu}^{2+}$ as catalyst, the lag time before the increase in CD was shortened $(33 \% ; P<0.01)$ in the lipoproteins of rats fed the MO-rich diet (89 (SE 4) and 60 (SE 5) min for $\mathrm{CO}$ and $\mathrm{MO}$, respectively) (Fig. 3 (b)). The oxidation rate of fatty acids was $47 \%$ lower $(P<0 \cdot 001)$ in lipoproteins from rats fed the MO-rich diet (152 (SE 12) $\mu \mathrm{mol} \mathrm{CD} / \mathrm{g}$ protein per min) compared with rats fed the CO-rich diet (289 (SE 10) $\mu \mathrm{mol} \mathrm{CD} / \mathrm{g}$ protein per $\mathrm{min}$ ) 


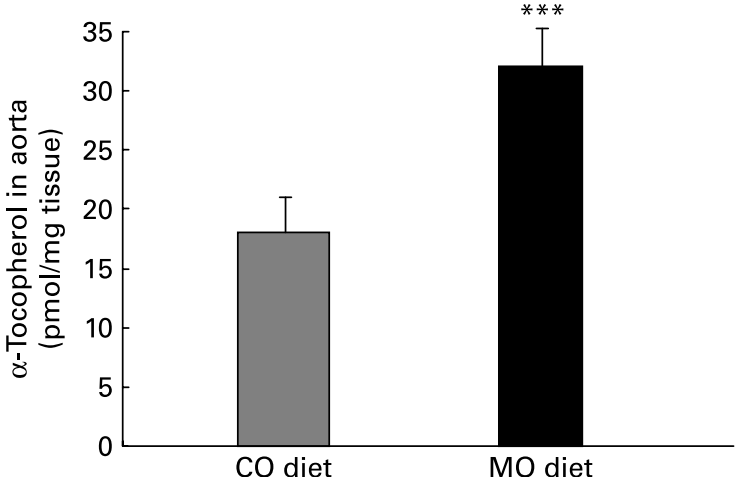

Fig. 2. Content of $\alpha$-tocopherol in aorta from rats fed a maize oil- (CO) or menhaden oil- (MO) rich diet, as measured by HPLC. Values are the means of six to seven rats per diet with their standard errors represented by vertical bars. ${ }^{* * *}$ Mean value was significantly different from that of the $\mathrm{CO}$ group $(P<0.001)$.

(Fig. 3 (c)). The maximum CD concentration was also reduced (27.0 (SE 1.1) v. 19.8 (SE 0.7) $\mathrm{mmol} \mathrm{CD/g}$ protein for $\mathrm{CO}$ and MO, respectively, $P<0.001$ ) (Fig. $3(\mathrm{~d})$ ).

When lipoproteins were exposed to the free radical generator AAPH, similar behaviour to $\mathrm{Cu}^{2+}$-induced lipoprotein oxidation was observed in the two dietary groups (Fig. 3(a)). The lag times were 172 (SE 15) and 122 (SE 15) min for CO and MO, respectively $(P<0.05)$ (Fig. $3(\mathrm{~b}))$, which represents a reduction of $29 \%$. The oxidation rates of fatty acids were 89 (SE 10) and 50 (SE 5) $\mu \mathrm{mol} \mathrm{CD/g}$ protein per min for $\mathrm{CO}$ and MO, respectively $(P<0.001)$, which represents a $43 \%$ decrease (Fig. 3(c)). The maximum CD concentration was also reduced (13.4 (SE 1.1) v. 7.1 (SE 0.8) $\mathrm{mmol} \mathrm{CD/g}$ protein for $\mathrm{CO}$ and MO, respectively, $P<0 \cdot 01$ ) (Fig. 3 (d)).

\section{Discussion}

The protective effect at cardiovascular level of long-chain $n-3$ PUFA present in fish and fish oils has been usually attributed to anti-arrhythmic, anti-thrombotic and anti-inflammatory effects, a reduction of blood pressure and TAG levels, improvement of endothelial function, and also prevention of atherosclerosis ${ }^{(9,11,12,27)}$.

The present paper gives for the first time new insights (tocopherol content in VLDL + LDL and aorta, ex vivo susceptibility of VLDL + LDL to oxidation by $\mathrm{Cu}^{2+}$ and AAPH, and $\mathrm{PON}-1$ ) into the physiological mechanism involved in the beneficial effects of increased endothelial NO production on the vascular wall in rats postulated by our group in

Table 3. Oxidative state in plasma*

(Mean values with their standard errors for six rats)

\begin{tabular}{lccccc}
\hline & \multicolumn{2}{c}{ Maize oil } & & \multicolumn{2}{c}{ Menhaden oil } \\
\cline { 2 - 3 } \cline { 3 - 4 } & Mean & SE & & Mean & SE \\
\hline TBARS $(\mu \mathrm{mol} / \mathrm{l})$ & 4.9 & 0.6 & & 5.9 & 0.5 \\
PON-1 $(\mathrm{U} / \mathrm{ml}) \dagger$ & 187 & 17 & & 168 & 8
\end{tabular}

TBARS, thiobarbituric acid-reactive substances; PON-1, paraoxonase-1.

${ }^{*}$ For details of diets and procedures, see Materials and methods.

tOne unit $(\mathrm{U})$ of $\mathrm{PON}-1$ corresponds to $1 \mathrm{nmol}$ paraoxon degradation $/ \mathrm{min}$. previous papers where the $5 \%$ of lipids of the diet were substituted by $\mathrm{CO}$ or $\mathrm{MO}^{(11,12)}$.

$\mathrm{NO}$ is a potent antioxidant ${ }^{(5,6)}$ but this activity can only be manifested when pro-oxidative reactions do not prevail, since NO may interact with $\mathrm{O}_{2}^{--}$to yield peroxynitrite, which promotes LDL oxidation ${ }^{(3)}$. Whether peroxynitrite is formed in vivo and exerts any physiological or pathological activity remains a subject of debate. We previously observed, in similar conditions, no increase in $\mathrm{O}_{2}^{--}$production from an MO-rich diet but induced NO-mediated vasorelaxation in tandem ${ }^{(11)}$. Thus, the final result may be a net gain of free $\mathrm{NO}^{(28)}$. In the present paper, we observe an endothelium-dependent NO increased production by $\mathrm{MO}$ that can be related to previous observations on increased NO concentrations in plasma ${ }^{(29)}$ and urine ${ }^{(30)}$ from human subjects or in plasma from rats ${ }^{(31)}$, both indices of NO-enhanced production by fish oil-supplemented diets.

It has been described that NO concentrates in lipophilic milieu by virtue of its uncharged character, low molecular mass, and relatively high lipid/water partition coefficient ${ }^{(32)}$. The NO generated at the vascular wall can act directly or through the generation of nitroalkenes by its reaction with PUFA, which eventually will release $\mathrm{NO}^{(33)}$. Moreover, nitroalkenes, which reduce inflammation ${ }^{(34)}$, may also contribute to the protection against atherosclerosis. We have observed that the MO-rich diet is associated with an increase in $\alpha$-tocopherol in the aortic tissue. As both the $\mathrm{CO}$ and $\mathrm{MO}$ diet were not deficient in vitamin $\mathrm{E}$ but contained similar tocopherol equivalents and in excess of requirements, the increased tocopherol content with $\mathrm{MO}$ is unlikely to be the cause of enhanced NO production through activation of endothelial NO synthase via phosphorylation of serine 1177 in the enzyme $^{(35)}$ but we attribute the increase in endothelial NO to the long-chain $n$-3 PUFA. The high levels of $\alpha$-tocopherol may be explained by two contributions. First, additional $R R R$, $R S R, R R S$ and $R S S$ isomers reached the aorta from the liver because of the excess of all-rac- $\alpha$-tocopherol supplemented to the MO diet $(20.7 \mathrm{mg} / \mathrm{kg}$ or $27.4 \%)$ compared with the high content of $\gamma$-tocopherol in the $\mathrm{CO}$ diet $(38.7 \mathrm{mg} / \mathrm{kg})$, despite the attempts to equalise tocopherol equivalents. Second, because of its antioxidant activity, NO can spare $\alpha$-tocopherol from oxidation ${ }^{(3,4)}$.

NO is able to diffuse to the lipidic core of LDL from the vascular wall ${ }^{(5)}$ and react with radical species at near diffusion-limited rate ${ }^{(4)}$. In the present study we in fact failed to detect a difference in the ex vivo ability of chemically generated NO to reach the lipidic core of lipoproteins enriched either with $n$-3 PUFA or $n$ - 6 PUFA. However, the greater amount of NO generated by the MO-rich diet compared with the CO-rich diet will be equally able to diffuse into VLDL + LDL and act as antioxidant in situ. We observed that native VLDL + LDL from MO-fed rats had a higher peroxidisability index and that these lipoproteins carry much less total PUFA than those isolated from animals fed a diet enriched in $\mathrm{CO}$ as observed by Thomas et al. ${ }^{(36)}$. The absence of differences in electrophoretic mobility of either whole lipoproteins or apo B-100, together with lack of difference in CD, TBARS and total antioxidant capacity in VLDL + LDL, and in TBARS and PON-1 in plasma from the two dietary groups, even at the high dose of fish oil used in the present paper, supports the idea that these native lipoproteins are not 
Table 4. Fatty acid content in VLDL + LDL in rats fed maize oil- or menhaden oil-rich diets†

(Mean values with their standard errors for six rats)

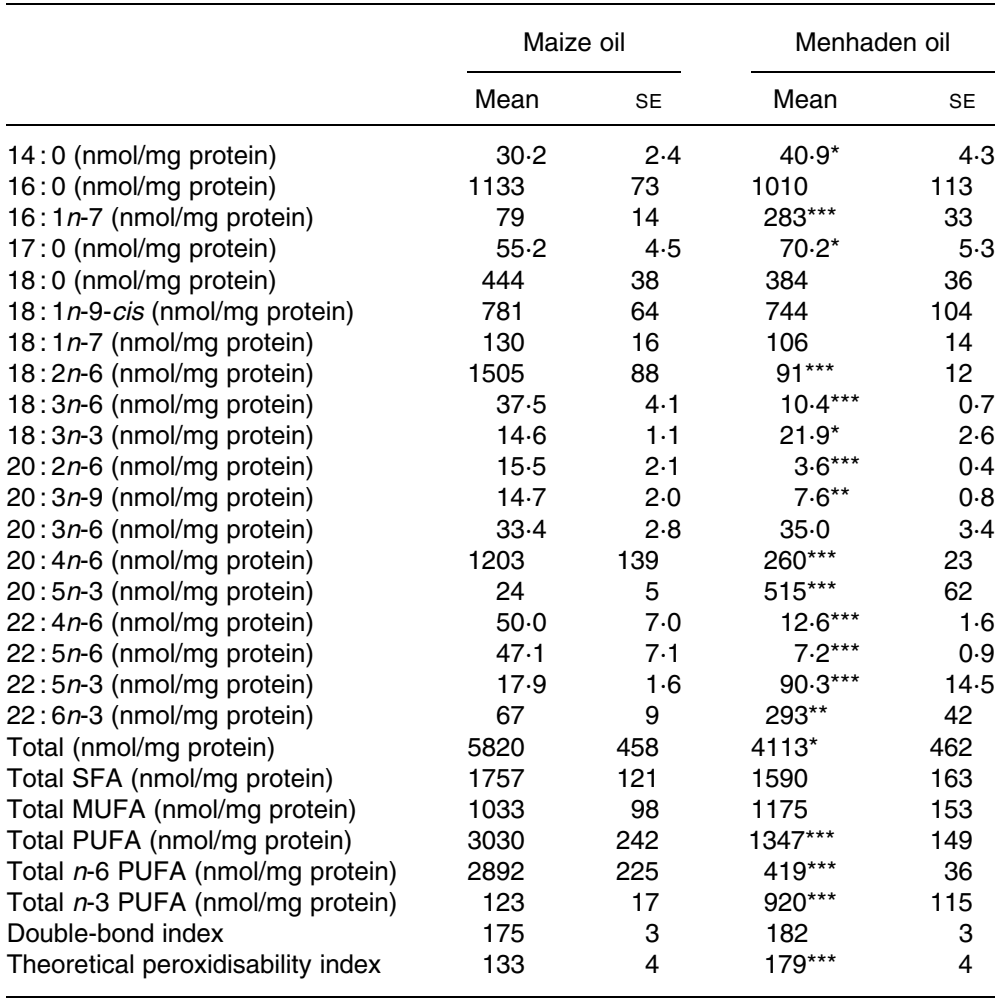

Mean value was significantly different from that of the maize oil group, ${ }^{\star} P<0.05$, ${ }^{\star \star} P<0.01$, ${ }^{\star \star \star \star} P<0.001$ (Student's $t$ test).

†For details of diets and procedures, see Materials and methods.

more oxidised in vivo in spite of a lower $\alpha$-tocopherol content. It should be emphasised that fish oil decreases the VLDL levels $^{(37)}$ and thus the $\alpha$-tocopherol plasma levels ${ }^{(37,38)}$. The absence of increased oxidation in native VLDL + LDL with an increased peroxidisability index compared with rats fed a diet enriched in $\mathrm{CO}$ may be due to the increased $\mathrm{NO}$ availability, which counteracts the decrease in $\alpha$-tocopherol. However, in the current in vivo study it was not possible to provide evidence of NO sparing $\alpha$-tocopherol.

NO is a potent antioxidant that can diffuse in situ into lipoproteins. However, as a gas it was absent in the ex vivo assays, and thus the antioxidant effect of the increased NO production on preventing lipoprotein oxidation cannot be demonstrated in those conditions. We observed alterations in the ex vivo susceptibility to oxidation in the MO group when oxidising agents such as $\mathrm{Cu}^{2+}$ and AAPH were used. The shortening of the lag time on rats fed an MO-rich diet can be related to the lower levels of $\alpha$-tocopherol. In this sense, Napolitano et al. ${ }^{(39)}$ detected a decrease in $\alpha$-tocopherol in chylomicron remnant preparations from rats treated with fish oil in comparison with rats treated with $\mathrm{CO}$. The reduction in oxidation rate $^{(40)}$ and maximum CD formation can be related either to a lower concentration of PUFA or to a more rapid decomposition of CD derived from n-3 PUFA. Reductions of lag time and oxidation rate were also shown in LDL from longchain $n-3$ PUFA-fed rats ${ }^{(14,36)}$ and human subjects ${ }^{(16,41,42)}$. These paradoxical results suggest the involvement of a differential distribution of fatty acids in LDL. The long chain $n-3$ PUFA are found in cholesteryl esters and TAG present in the core of LDL, while linoleic acid is found in surface phospholipids $^{(39)}$. We can consider, in agreement of Higdon et al. ${ }^{(14)}$, that the overall total oxidation of the VLDL + LDL particles was not increased by the MO-rich diet. However, results from different studies are contradictory. While some researches reported no difference in susceptibility of LDL particles to oxidation with fish-oil supplementation ${ }^{(29,43,44)}$, others found a decrease ${ }^{(45)}$ or even an increase ${ }^{(27,46)}$. Differences in study design, the supplementation dosage, the use of unreliable tests or of oxidised dietary oils may explain partly these inconsistent results.

We have to take into consideration that in the oxidation of lipoproteins ex vivo, $\alpha$-tocopherol and total PUFA are involved and that NO is not present. We have thus demonstrated by different techniques that native lipoproteins were not more oxidised and that the resistance of VLDL + LDL to oxidation ex vivo does not reflect their in vivo behaviour as relevant factors such as $\mathrm{NO}$ are lacking.

HDL-associated PON-1 prevents LDL oxidation ${ }^{(7)}$ and represents another mechanism by which long-chain $n$-3 PUFA could exert their beneficial effect at cardiovascular level. No information is currently available on the effects of fish oil on PON-1 activity in healthy humans or animals and the lack of any effect in the present study rules out an in vivo modulation of LDL oxidation by fish oil via HDL. 


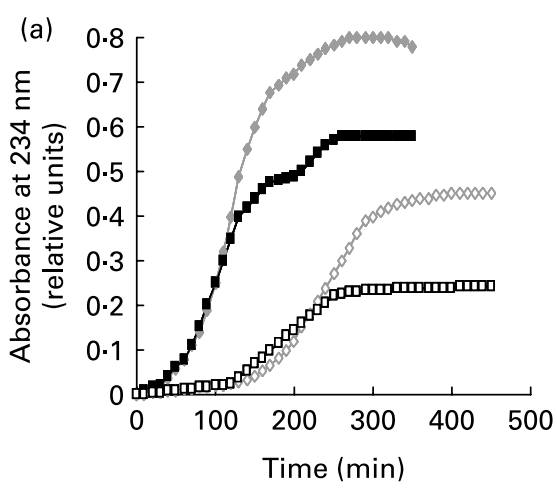

(c)

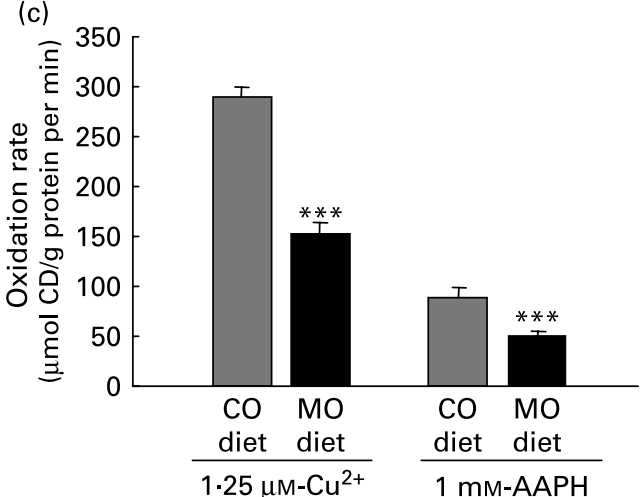

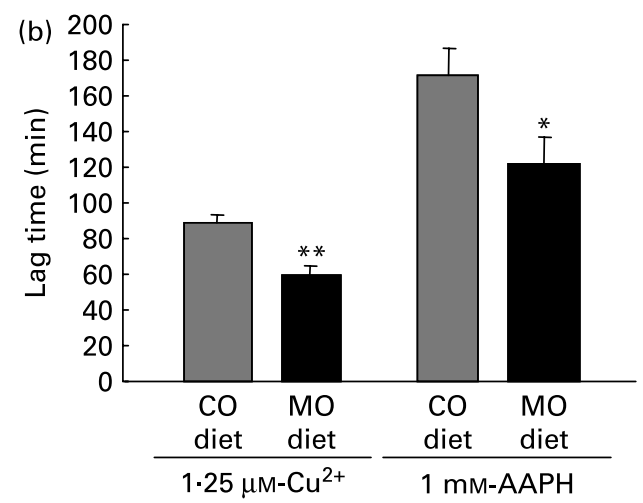

(d)

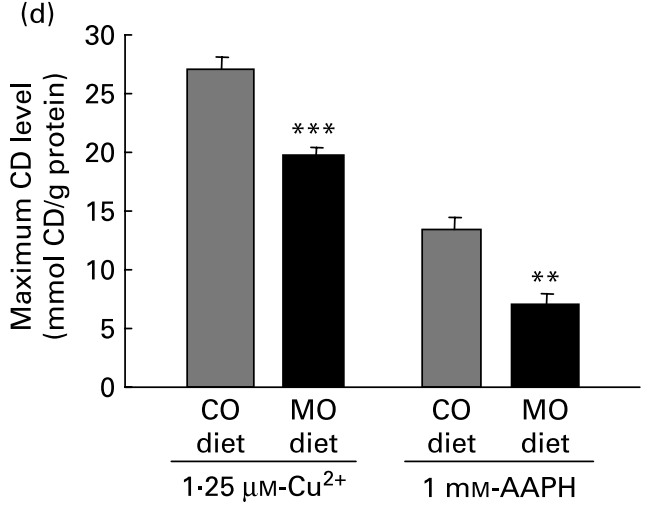

Fig. 3. Susceptibility of VLDL + LDL to oxidation from rats fed a maize oil (CO)- or menhaden oil (MO)-rich diet, measured in terms of conjugated diene (CD) generation. This process was continuously monitored by the change in absorbance at $234 \mathrm{~nm}$. (a) Representative curve. $(---)$, Cu ${ }^{2+}$-treated VLDL + LDL from COfed rats; $(-\mathbf{-}-), \mathrm{Cu}^{2+}$-treated VLDL + LDL from MO-fed rats; $(-\diamond-), 2,2^{\prime}$-azobis (2-amidinopropane) dihydrochloride (AAPH)-treated VLDL + LDL from CO-fed rats; (- $\square-$ ), AAPH-treated VLDL + LDL from MO-fed rats. (b) Lag time; (c) oxidation rate; (d) maximum CD level. Values are means with their standard errors represented by vertical bars (two replicates from six rats per diet). Mean value was significantly different from that of the $C O$ group: ${ }^{\star} P<0.05$, ${ }^{\star \star} P<0.01$, ${ }^{\star \star \star} P<0.001$.

Moreover, the similar levels of TBARS and PON-1 in plasma corroborate the absence of increased lipid peroxidation by a fish oil-rich diet.

It has been demonstrated that fish oil has a broad spectrum of beneficial effects. The increased endothelial NO production, induced in vivo, is indicative of a compensatory protective mechanism in inflammatory and vascular diseases and may be related to an increase in $\alpha$-tocopherol. In the present paper, we demonstrate beneficial effects of fish oil in aortic tissue and non-deleterious effects on VLDL + LDL in spite of a higher peroxidisability index. It is likely that the fish oil-mediated NO increase and the absence of differences in the rate of diffusion into the VLDL + LDL lipidic core are additional crucial mechanisms involved in the anti-atherogenic properties of fish and fish oils.

\section{Acknowledgements}

There is no conflict of interest. The authors thank Robin Rycroft for valuable assistance in the preparation of the manuscript. The present study was supported by the Comisión Interministerial de Ciencia y Tecnología (PM 980182) and the Generalitat de Catalunya (2005SGR269). We would also like to thank the Universitat de Barcelona for supporting $\mathrm{D}$. L.
D. L., K. C. and M. T. M. performed the assays on biological activities, M. M., A. D. and H. R. were in charge of NO diffusion studies into the lipidic core of VLDL + LDL and J. I. R.-S. evaluated the fatty acid content of oils and VLDL + LDL.

\section{References}

1. Chisolm GM \& Steinberg D (2000) The oxidative modification hypothesis of atherogenesis: an overview. Free Radic Biol Med 28, 1815-1826.

2. Rubbo H, Radi R, Trujillo M, Telleri R, Kalyanaraman B, Barnes S, Kirk M \& Freeman BA (1994) Nitric oxide regulation of superoxide and peroxynitrite-dependent lipid peroxidation. Formation of novel nitrogen-containing oxidized lipid derivatives. J Biol Chem 269, 26066-26075.

3. Botti H, Batthyany C, Trostchansky A, Radi R, Freeman BA \& Rubbo H (2004) Peroxynitrite-mediated $\alpha$-tocopherol oxidation in low-density lipoprotein: a mechanistic approach. Free Radic Biol Med 36, 152-162.

4. O’Donnell VB, Chumley PH, Hogg N, Bloodsworth A, DarleyUsmar VM \& Freeman BA (1997) Nitric oxide inhibition of lipid peroxidation: kinetics of reaction with lipid peroxyl radicals and comparison with $\alpha$-tocopherol. Biochemistry 36, 15216-15223.

5. Denicola A, Batthyany C, Lissi E, Freeman BA, Rubbo H \& Radi R (2002) Diffusion of nitric oxide into low density lipoprotein. J Biol Chem 277, 932-936. 
6. Trostchansky A, Batthyany C, Botti H, Radi R, Denicola A \& Rubbo H (2001) Formation of lipid-protein adducts in low-density lipoproteins by fluxes of peroxynitrite and its inhibition by nitric oxide. Arch Biochem Biophys 395, 225-232.

7. Aviram M, Hardak E, Vaya J, Mahmood S, Milo S, Hoffman A, Billicke S, Draganov D \& Rosenblat M (2000) Human serum paraoxonase (PON1) Q and R selectively decrease lipid peroxides in human coronary and carotid atherosclerotic lesions: PON1 esterase and peroxidase-like activities. Circulation 101, 2510-2517.

8. Calder PC (2004) n-3 Fatty acids and cardiovascular disease: evidence explained and mechanisms explored. Clin Sci 107, $1-11$.

9. Connor SL \& Connor WE (1997) Are fish oils beneficial in the prevention and treatment of coronary artery disease? Am J Clin Nutr 66, 1020S-1031S.

10. Tagawa H, Shimokawa H, Tagawa T, Kuroiwa-Matsumoto M, Hirooka Y \& Takeshita A (1999) Long-term treatment with eicosapentanoic acid augments both nitric oxide-mediated and non-nitric oxide-mediated endothelium-dependent forearm vasodilatation in patients with coronary artery disease. J Cardiovasc Pharmacol 33, 633-640.

11. López D, Caballero C, Sánchez J, Puig-Parellada P \& Mitjavila MT (2001) Free radical production in aortic rings from rats fed a fish oil-rich diet. Am J Physiol Heart Circ Physiol 280, 2929-2935.

12. López D, Orta X, Casós K, Sáiz MP, Puig-Parellada P, Farriol M \& Mitjavila MT (2004) Upregulation of endothelial nitric oxide synthase in rat aorta after ingestion of fish oil-rich diet. Am J Physiol Heart Circ Physiol 287, H567-H572.

13. Okuyama H, Kobayashi $\mathrm{T} \&$ Watanabe $S$ (1996) Dietary fatty acids - the $n-6 / n-3$ balance and chronic elderly diseases. Excess linoleic acid and relative $n-3$ deficiency syndrome seen in Japan. Prog Lipid Res 35, 409-457.

14. Higdon JV, Du SH, Lee YS, Wu T \& Wander RC (2001) Supplementation of postmenopausal women with fish oil does not increase overall oxidation of LDL ex vivo compared to dietary oils rich in oleate and linoleate. J Lipid Res 42, 407-418.

15. Moreno JJ \& Mitjavila MT (2003) The degree of unsaturation of dietary fatty acids and the development of atherosclerosis. J Nutr Biochem 14, 182-195.

16. Wander RC, Du SH, Ketchum SO \& Rowe KE (1996) Effects of interaction of $R R R$-tocopheryl acetate and fish oil on lowdensity-lipoprotein oxidation in postmenopausal women with and without hormone-replacement therapy. Am J Clin Nutr 63, 184-193.

17. Fischkoff S \& Vanderkooi JM (1975) Oxygen diffusion in biological and artificial membranes determined by the fluorochrome pyrene. J Gen Physiol 65, 663-676.

18. Lepage G \& Roy CC (1986) Direct transesterification of all classes of lipids in a one-step reaction. J Lipid Res 27, 114-120.

19. Ruiz-Sanz JI, Navarro R, Martinez R, Martin C, Lacort M, Matorras R \& Ruiz-Larrea MB (2001) 17 $\beta$-Estradiol affects in vivo the low density lipoprotein composition, particle size, and oxidizability. Free Radic Biol Med 31, 391-397.

20. Ha YC \& Barter PJ (1985) Rapid separation of plasma lipoproteins by gel permeation chromatography on agarose gel Superose 6B. J Chromatogr 341, 154-159.

21. Esterbauer H, Gebicki J, Puhl H \& Jürgens G (1992) The role of lipid peroxidation and antioxidants in oxidative modification of LDL. Free Radic Biol Med 13, 341-390.

22. Vanin AF (1999) Iron diethyldithiocarbamate as spin trap for nitric oxide detection. Methods Enzymol 301, 269-279.

23. Yagi K (1984) Assay for blood plasma or serum. Methods Enzymol 105, 328-331.

24. Beltowski J, Wójcicka G \& Marciniak A (2002) Species- and substrate-specific stimulation of human plasma paraoxonase 1
(PON1) activity by high chloride concentration. Acta Biochim Pol 49, 927-936.

25. Shapiro SS, Mott DJ \& Machlin LJ (1984) Kinetic characteristics of $\beta$-carotene uptake and depletion in rat tissue. $J$ Nutr 114, 1924-1933.

26. Carbonneau MA, Cartron E, Léger CL, Senglat C \& Descomps B (2002) New insight on the relationship between LDL composition, associated proteins, oxidative resistance and preparation procedure. Free Radic Res 36, 127-142.

27. Mesa MD, Buckley R, Minihane AM \& Yaqoob P (2004) Effects of oils rich in eicosapentaenoic and docosahexaenoic acids on the oxidizability and thrombogenicity of low-density lipoprotein. Atherosclerosis 175, 333-343.

28. Liochev SI \& Fridovich I (2002) Superoxide and nitric oxide: consequences of varying rates of production and consumption: a theoretical treatment. Free Radic Biol Med 33, 137-141.

29. Piolot A, Blache D, Boulet L, Fortin LJ, Dubreuil D, Marcoux C, Davignon J \& Lussier-Cacan S (2003) Effect of fish oil on LDL oxidation and plasma homocysteine concentration in health. J Lab Clin Med 141, 41-49.

30. Harris WS, Rambjør GS, Windsor SL \& Diederich D (1997) $n-3$ Fatty acids and urinary excretion of nitric oxide metabolites in humans. Am J Clin Nutr 65, 459-464.

31. Erdogan H, Fadillioglu E, Ozgocmen S, Sogut S, Ozyurt B, Akyol O \& Ardicoglu O (2004) Effect of fish oil supplementation on plasma oxidant/antioxidant status in rats. Prostaglandins Leukot Essent Fatty Acids 71, 149-152.

32. Denicola A, Souza JM, Radi R \& Lissi E (1996) Nitric oxide diffusion in membranes determined by fluorescence quenching. Arch Biochem Biophys 328, 208-212.

33. Schopfer FJ, Baker PRS, Giles G, et al. (2005) Fatty acid transduction of nitric oxide signaling. Nitrolinoleic acid is a hydrophobically stabilized nitric oxide donor. $J$ Biol Chem 280, 19289-19297.

34. Cui T, Schopfer FJ, Zhang J, et al. (2006) Nitrated fatty acids: endogenous anti-inflammatory signaling mediators. J Biol Chem 281, 35686-35698.

35. Heller R, Werner-Felmayer G \& Werner ER (2004) $\alpha$-Tocopherol and endothelial nitric oxide synthesis. Ann N Y Acad Sci 1031, 74-85.

36. Thomas MJ, Thornburg T, Manning J, Hooper K \& Rudel LL (1994) Fatty acid composition of low-density lipoprotein influences its susceptibility to autoxidation. Biochemistry 33, $1828-1834$.

37. Childs MT, King IB \& Knopp RH (1990) Divergent lipoprotein responses to fish oils with various ratios of eicosapentaenoic acid and docosahexaenoic acid. Am J Clin Nutr 52, 632-639.

38. Bjørneboe A, Bjørneboe GE \& Drevon CA (1990) Absorption, transport and distribution of vitamin E. J Nutr 120, 233-242.

39. Napolitano M, Bravo E, Avella M, Chico Y, Ochoa B, Botham KM \& Rivabene R (2004) The fatty acid composition of chylomicron remnants influences their propensity to oxidate. Nutr Metab Cardiovasc Dis 14, 241-247.

40. Bonanome A, Pagnan A, Biffanti S, Opportuno A, Sorgato F, Dorella M, Maiorino M \& Ursini F (1992) Effect of dietary monounsaturated and polyunsaturated fatty acids on the susceptibility of plasma low density lipoproteins to oxidative modification. Arterioscler Thromb Vasc Biol 12, 529-533.

41. Sorensen NS, Marckmann P, Hoy CE, van Duyvenvoorde W \& Princen HM (1998) Effect of fish-oil-enriched margarine on plasma lipids, low-density-lipoprotein particle composition, size, and susceptibility to oxidation. Am J Clin Nutr 68, $235-241$.

42. Wander RC, Du SH \& Thomas DR (1998) Influence of longchain polyunsaturated fatty acids on oxidation of low density lipoprotein. Prostaglandins Leukot Essent Fatty Acids 59, $143-151$. 
43. Brude IR, Drevon CA, Hjermann I, et al. (1997) Peroxidation of LDL from combined-hyperlipidemic male smokers supplied with omega-3 fatty acids and antioxidants. Arterioscler Thromb Vasc Biol 17, 2576-2588.

44. Higgins S, Carroll YL, McCarthy SN, Corridan BM, Roche HM, Wallace JM, O’Brien NM \& Morrissey PA (2001) Susceptibility of LDL to oxidative modification in healthy volunteers supplemented with low doses of $n-3$ polyunsaturated fatty acids. Br J Nutr 85, 23-31.
45. Oostenburg GS, Mensink RP, Hardeman MR, De Vries T, Brouns F \& Hornstra G (1997) Exercise performance, red blood cell deformability, and lipid peroxidation, effects of fish oil and vitamin E. J Appl Physiol 83, 746-752.

46. Leigh-Firbank EC, Minihane AM, Leake DS, Wright JW, Murphy MC, Griffin BA \& Williams CM (2002) Eicosapentaenoic acid and docosahexaenoic acid from fish oils: differential associations with lipid responses. Br J Nutr 87, $435-445$. 